$\mathrm{AB} 0907$

TREATMENT PATTERNS IN PSORIATIC ARTHRITIS IN US AND EUROPE: RESULTS FROM A REAL-WORLD INTERNATIONAL SURVEY

A.-M. Orbai ${ }^{1}$, L. Gossec ${ }^{2}$, S. Lobosco ${ }^{3}$, R. Moon ${ }^{3}$, O. Massey ${ }^{3}$, J. Piercy ${ }^{3}$, J. C. Cappelleri ${ }^{4}$, L. Fallon ${ }^{4}$, P. Young ${ }^{4}$, A.B. Romero ${ }^{4}$, M.-A. Hsu' ${ }^{4}{ }^{1}$ John Hopkins University, Baltimore, MD, USA; ${ }^{2}$ Sorbonne Universités, Paris, France; ${ }^{3}$ Adelphi Real World, Bollington, UK; ${ }^{4}$ Pfizer, Groton, CT, USA

Background: With the availability of a greater range of Psoriatic Arthritis (PsA) treatment options, it is increasingly necessary to understand their use and impact on disease control in real-world practice.

Objectives: To assess treatment patterns and their impact on clinical outcomes among PsA patients currently receiving conventional/targeted synthetic diseasemodifying anti-rheumatic drugs (cs/tsDMARD) or biologic DMARD (bDMARD). Methods: A point in time survey was conducted in 2015 across the US, France, Germany, Italy, Spain and UK. Patients had physician-confirmed PsA and had to have been receiving their current cs/tsDMARD (bio naïve) or bDMARD (1st or 2nd line) for $\geq 6$ months. Physicians provided information on demographics, treatment history, disease severity, clinical measures included body surface area (BSA), joint count, flare/remission status. Student t-tests, Pearson's chi-squared and Fisher's exact tests were used to compare physician-reported patient profile variables, clinical status and treatment outcomes.

Results: 519 physicians (331 rheums, 188 derms) provided data for 2467 PsA patients, 1463 of whom met the inclusion criteria (1136 EU, 327 US). No significant differences were observed between EU and US patients in demographics (male 52.6\%, mean age 49.0 years), disease duration 6.3 years; disease severity $29.1 \%$ moderate to severe). In the EU, $32.3 \%$ patients were on cs/tsDMARDs, $55.4 \%$ 1st-line bDMARD, $12.3 \%$ 2nd-line bDMARD vs $21.7 \%, 58.4 \%, 19.9 \%$ respectively in the US.

Time in months $(\mathrm{mo})$ from diagnosis to first cs/tsDMARD was similar in the EU and US (EU mean $4.7 \mathrm{mo}$; US $8.1 \mathrm{mo}, \mathrm{p}=0.24$ ), from $1 \mathrm{st} \mathrm{cs} / \mathrm{tsDMARD}$ to $1 \mathrm{st}$ bio (EU $37.4 \mathrm{mo}$; US $29.4 \mathrm{mo}, \mathrm{p}=0.15$ ). Patients in the EU received more cs/ tsDMARDs prior to bDMARD initiation than US patients (mean $1.4 \mathrm{v} 0.8$; $\mathrm{p}<0.001)$. US patients were more likely to have bDMARD without combination cs/ tsDMARDs (US $65.1 \%$ vs EU $52.3 \%$; $p=0.004$ ).

Patients receiving cs/tsDMARDs had a worse clinical profile than those on 1st-line bDMARD in all areas other than joint count. Patients on 2nd-line bDMARD had more symptoms, more affected joints and more likely to flare vs 1st-line bDMARD. They had more affected joints but were less likely to flare vs cs/tsDMARD. These findings were directionally similar in the EU and US (table 1). BSA was higher for cs/tsDMARD patients than for any bDMARD patients.

Table 1

\begin{tabular}{|c|c|c|c|c|c|c|}
\hline & $\begin{array}{c}\text { Current } \\
\text { cs/ } \\
\text { tsDMARD } \\
(n=438)\end{array}$ & $\begin{array}{c}\text { Current } \\
\pm \text { Line bDMARD } \\
(n=820)\end{array}$ & $\begin{array}{l}\text { P value } \\
\text { (cs/ } \\
\text { tsDMARD } \\
\text { v } 1 \text { st } \\
\text { Line } \\
\text { bDMARD) }\end{array}$ & $\begin{array}{c}\text { Current } \\
\text { 2nd Line } \\
\text { bDMARD } \\
(n=205)\end{array}$ & $\begin{array}{c}\text { P value } \\
\text { (2nd Line } \\
\text { bDMARD } \\
\text { v cs/ } \\
\text { tsDMARD }\end{array}$ & $\begin{array}{c}\text { P value } \\
\text { (2nd v } \\
\underline{1} \text { st Line } \\
\text { bDMARD) }\end{array}$ \\
\hline $\begin{array}{l}\text { Mean No. } \\
\text { of PsA } \\
\text { Symptoms }\end{array}$ & 1.7 & 1.4 & $<0.001$ & 1.9 & 0.378 & $<0.001$ \\
\hline $\begin{array}{l}\text { Mean No. } \\
\text { of Joints } \\
\text { Affected }\end{array}$ & 3.2 & 3.3 & 0.531 & 4.0 & $<0.001$ & $<0.001$ \\
\hline $\begin{array}{l}\text { Patients } \\
\text { currently } \\
\text { flaring }\end{array}$ & $6.7 \%$ & $3.4 \%$ & 0.032 & $5.4 \%$ & $<0.001$ & $<0.001$ \\
\hline $\begin{array}{l}\text { Currently } \\
\text { not in } \\
\text { Remission }\end{array}$ & $60.5 \%$ & $39.5 \%$ & $<0.001$ & $45.9 \%$ & $<0.001$ & 0.112 \\
\hline Mean BSA & $11.4 \%$ & $7.8 \%$ & $<0.001$ & $8.6 \%$ & 0.001 & 0.583 \\
\hline
\end{tabular}

Conclusions: Only $39 \%-60 \%$ of patients were considered by physicians as in remission, revealing a considerable unmet need in both the EU and US in patients treated with cs/tsDMARDs and bDMARDs. Further research is needed to identify patients on cs/tsDMARDs who may be a candidate for advanced therapy and to recognise patients who might fail on bDMARD who therefore may benefit from a different therapeutic alternative.

Disclosure of Interest: A.-M. Orbai Grant/research support from: AbbVie, Celgene, Eli Lilly, Horizon, Janssen, Novartis, Pfizer, Consultant for: Eli Lilly, Janssen, Novartis, Pfizer, UCB, L. Gossec Grant/research support from: UCB, Lilly,
Pfizer, BMS, Consultant for: AbbVie, BMS, Celgene, Janssen, Novartis, Pfizer, Roche UCB, S. Lobosco Employee of: Adelphi Real World, R. Moon Employee of: Adelphi Real World, O. Massey Employee of: Adelphi Real World, J. Piercy Employee of: Adelphi Real World, J. Cappelleri Shareholder of: Pfizer, Employee of: Pfizer, L. Fallon Shareholder of: Pfizer, Employee of: Pfizer, P. Young Employee of: Pfizer, A. Romero Employee of: Pfizer, M.-A. Hsu Shareholder of: Pfizer, Employee of: Pfizer

DOI: 10.1136/annrheumdis-2018-eular.3060

\section{AB0908 ABILITY OF THE REDUCTIVE X-RAY SCORE FOR PSORIATIC ARTHRITIS (REXSPA) TO DETECT CHANGE IN AN OBSERVATIONAL COHORT OF PATIENTS WITH PSA}

A. Antony ${ }^{1}$, A. Allard ${ }^{1}$, G. Shaddick ${ }^{2}$, D. Jadon ${ }^{3}$, C. Cavill ${ }^{1,4}$, E. Korendowych ${ }^{1}$, N. McHugh ${ }^{1,4}$, W. Tillett ${ }^{1,4} .{ }^{1}$ Rheumatology, Royal National Hospital for Rheumatic Diseases, Bath; ${ }^{2}$ Mathematical Sciences, University of Exeter, Exeter,

${ }^{3}$ Rheumatology, Cambridge University Hospitals, Cambridge; ${ }^{4}$ Pharmacy and Pharmacology, University of Bath, Bath, UK

Background: The measurement of radiographic joint damage is important in characterising disease severity, progression, and prognosis in psoriatic arthritis (PsA). Existing radiographic measures are time-consuming to perform, leading to limited data collection from existing longitudinal observational studies.

Objectives: We have previously proposed a Reductive X-ray Score for Psoriatic Arthritis (ReXSPA) ${ }^{1}$ as more feasible method, and in this study set out to examine the sensitivity of ReXSPA in a new cohort of patients.

Methods: A retrospective sample of 28 patients who had hand and feet radio graphs at 3 time points (5 years before $\left[\mathrm{T}^{0}\right]$, at the time of $\left[\mathrm{T}^{1}\right]$, and 5 years pos $\left[\mathrm{T}^{2}\right]$ commencement of anti-TNF treatment) were taken from the Bath longitudinal PsA cohort. Radiographs were scored for erosion, joint space narrowing and proliferation to calculate the Sharp-van der Heijde modified method (VDH) and ReXSPA scores. A sample of 9 radiographs were scored by all assessors (WT $A A$ and $A A$ ) to determine inter- and intra-rater reliability using intra-class correlation coefficients (ICC). Sensitivity to change was determined from timepoint $T^{0}$ to $\mathrm{T}^{2}$ using the Standardised Response Mean (SRM) and Smallest Detectable Change (SDC)

Results: The patients' mean age (SD) at $\mathrm{T}^{0}$ was 61 years (13.4), the mean dis ease duration was 11.2 years (11.14). Patients were followed up for a mean (SD) of 10.2 years (2.76). Overall inter- and intra-rater reliability for ReXSPA and VDH were 0.80 and $>0.92$ and 0.91 and $>0.90$ respectively. The median (IQR) of ReXSPA score was $8.5(1-14), 12.5(5-20)$ and $14.5(8-36)$ at $\mathrm{T}^{0}, \mathrm{~T}^{1}$, and T2 respectively. The percentage SDC was 0.91 for the ReXSPA method and 0.77 for the VDH method, and the SRMs were 0.92 and 0.87 respectively (table 1 ), demonstrating the sensitivity of both methods in detecting change. There was a trend towards slowing in radiographic progression following the initiation of TNF-inhibitors, but ReXSPA was less sensitive compared to the VDH and was not able to detect a significant change in the rate of progression post-TNF inhibition ( $p$ 0.08) (Graphic 1)

Abstract AB0908 - Table 1. Sensitivity to change of each scoring method

\begin{tabular}{lcccccc}
\hline Method & $\begin{array}{c}\text { Mean } \\
\text { Change }\end{array}$ & $\begin{array}{c}\text { SD of } \\
\text { change }\end{array}$ & SEM & SRM & SDC & $\begin{array}{c}\text { SDC as\% of total } \\
\text { score }\end{array}$ \\
\hline VDH & 22.11 & 19.14 & 3.62 & 0.87 & 4.09 & 0.77 \\
Erosion & 7.29 & 10.62 & 2.01 & 1.46 & 2.27 & 0.71 \\
JSN & 16.96 & 15.17 & 2.87 & 0.89 & 3.24 & 1.56 \\
ReXPSA & 10.9 & 10.0 & 1.89 & 0.92 & 2.14 & 0.91 \\
Erosion & 3.21 & 5.31 & 1.00 & 1.65 & 1.13 & 1.03 \\
JSN & 6.36 & 5.11 & 0.97 & 0.80 & 1.09 & 1.24 \\
Proliferation & 0.96 & 2.32 & 0.44 & 2.40 & 0.50 & 1.39 \\
\hline
\end{tabular}

Sharp-van der Heijde modified method (VDH), Standard deviation (SD), Standard error of mean (SEM), Standardised response mean (SRM), Smallest detectable change (SDC). 


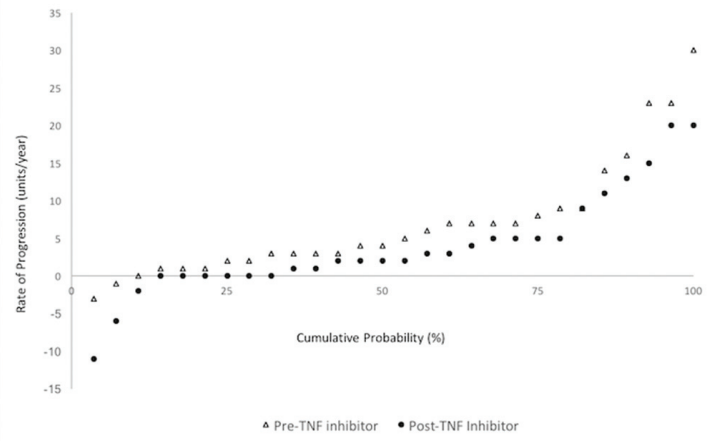

Abstract AB0908 - Figure 1. Cumulative probability plot demonstrating ReXSPA progression pre- and post- TNF inhibition

Conclusions: The RexSPA is a reliable and sensitive alternate scoring method for the detection of radiographic progression in an observational cohort of patients with PsA, but not as sensitive to change as the VDH method.

\section{REFERENCE:}

[1] Tillett W, et al. (2016) Novel Composite Radiographic Score for Longitudinal Observational Studies of Psoriatic Arthritis: A Proof-of-concept Study. J Rheum; 43(2):367-370

Disclosure of Interest: None declared

DOI: 10.1136/annrheumdis-2018-eular.4039

\begin{tabular}{l|l}
\hline AB0909 & CERTOLIZUMAB PEGOL'S EFFECTIVENESS, \\
RETENTION RATE AND SAFETY IN PSORIATIC \\
ARTHRITIS. ROUTINE CLINICAL PRACTICE DATA
\end{tabular}

A. Conesa Mateos ${ }^{1}$, M. Fernandez-Prada ${ }^{2}$, R. Expósito-Molinero ${ }^{3}$, J. Campos $^{2}$ Esteban $^{4}$, P. Rubio Muñoz ${ }^{5}$, J.R. Lamua-Riazuelo ${ }^{6}$, P. Navarro-Alonso ${ }^{7}$, P. Ahijado Guzmán $^{6}$, C.M. Gonzalez Fernandez ${ }^{8}$, on behalf of RENACER Study Group.

${ }^{1}$ Rheumatology, Hospital Clinico Universitario, Valencia; ${ }^{2}$ Rheumatology, Hospital Universitario de Guadalajara, Guadalajara; ${ }^{3}$ Rheumatology, Hospital Comarcal de Laredo, Laredo; ${ }^{4}$ Rheumatology, Hospital Universitario Puerta de Hierro, Madrid;

${ }^{5}$ Rheumatology, Hospital Universitari Germans Trias i Pujol, Badalona;

${ }^{6}$ Rheumatology, Hospital del Henares, Alcala de Henares; ${ }^{7}$ Rheumatology, Hospital de Fuenlabrada, Fuenlabrada; ${ }^{8}$ Rheumatology, Hospital General Universitario Gregorio Marañón, Madrid, Spain

Background: Certolizumab pegol (CZP) is the only antiTNF pegylated without FC available for patients with psoriatic arthritis (PsA). The efficacy and safety of CZP in clinical trials is known, but there are few published data on the effectiveness of CZP in a setting of usual clinical practice.

Objectives: To evaluate the effectiveness and safety of Certolizumab Pegol $(\mathrm{CZP})$ in a real in PsA patients.

Methods: Multicentric cohort of PsA patients treated with CZP according routine clinical practice. Study approved by local Ethics Committee. Maximum time of observation was 12 months. Effectiveness variables: SJC, TJC, PtGA (Patient Global Assesment) and DAS28-CRP. Safety variables: discontinuation rate.

Results: 262 patients with PsA were included: $43.5 \%$ male, mean (SD) age 49.9 (11.9) years, mean (Q1-Q3) disease duration 6.9 (1.9-9.3) years, 14.9\% of patients HLAB27 positive, mean (SD) IMC $\left(\mathrm{kg} / \mathrm{m}^{2}\right) 26.9$ (4.7), never smokers 70.3\%. Extra-articular manifestations ever: Psoriasis (90\%; PASI $\geq 1040.9 \%$ ), enthesitis $(44.4 \%)$, dactilytis $(41.9 \%)$, nail disease $(32 \%)$, inflammatory bowel diseases $(4.9 \%$ ). $37.3 \%$ of the PsA patients had bone erosions and $3 \%$ arthritis mutillans. 48.9 patients received 1 prior csDMARD and $52.1 \%$ at least 2 csDMARD. Prior bDMARD: $28.4 \%$ none; $38.1 \% 1,33.5 \% \geq 2.29 .6 \%$ of PsA patients received CZP in monotherapy. Mean time on treatment with CZP 10 months.

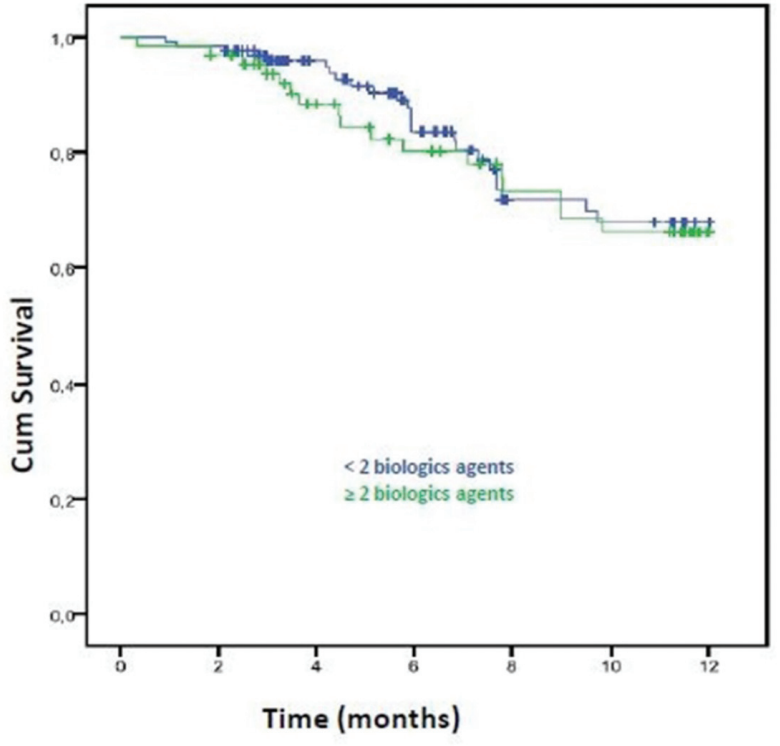

Abstract AB0909 - Figure 1. CZP retention rate and biologics exposure $\left(\mathrm{n}^{\circ}\right.$ of previous biologics)

Statistically significant differences in SJC, TJC and DAS28-CRP were observed at the last visit comparing with baseline (table 1). Percentage of patients with enthesitis at baseline (25.4\%) decrease to $9.5 \%$ at the last visit; $73.2 \%$ of the patients had a resolution of the enthesitis (MASES $=0$ ). The percentage of patients with dactilytis at baseline $(29.1 \%$ ) decrease to $8.6 \%$ in the last visit; $82.5 \%$ of these patients had a resolution of the dactilytis. Statistically significant reduction of patients with nail disease was observed from $30.6 \%$ to $16.4 \%$.

According to Kaplan-Meier analysis, the drug survival of CZP was $78.2 \%$, and no differences were observed in patients who received CZP as first/second biologic or after more than 1 failure to other biologicals agents (Figure1).

262 patients were included in the safety analysis, $21.8 \%$ withdrawn treatment: $12.6 \%$ due to lack of effectiveness, $5.3 \%$ due to intolerance and $3.8 \%$ other reasons.

Abstract AB0909 - Table 1. Effectiveness

\begin{tabular}{lcc}
\hline & Baseline & Last visit \\
\hline DAS28; mean & $4.6(0.9)$ & $3.8(1.0)^{*}$ \\
(SD) & & \\
TJC; mean (SD) & $7.2(5.1)$ & $4.0(4.0)^{*}$ \\
SJC; mean (SD) & $5.0(3.7)$ & $2.8(2.8)^{*}$ \\
PtGA; mean (SD) & $6.9(1.7)$ & $4.3(2.5)$ \\
& & $*$ \\
\hline
\end{tabular}

${ }^{*} \mathrm{p}<0,001$, Wilcoxon's test

Conclusions: In this study of routine clinical practice CZP was effective in patients with PsA, with a significant decrease in DAS28-CRP and the percentage of patients with enthesitis and dactylitis. The retention rate of certolizumab pegol was not affected by the number of previous biological treatments.

Disclosure of Interest: A. Conesa Mateos: None declared, M. FernandezPrada: None declared, R. Expósito-Molinero: None declared, J. Campos Esteban: None declared, P. Rubio Muñoz: None declared, J. R. Lamua-Riazuelo: None declared, P. Navarro-Alonso: None declared, P. Ahijado Guzmán: None declared, C. Gonzalez Fernandez Consultant for: Celgene, MSD, Novartis, Janssen, Speakers bureau: UCB, Abbvie, Pfizer, BMS, Roche, Celgene, Janssen DOI: 10.1136/annrheumdis-2018-eular.5919 


\section{AB0910 LONG-TERM GOLIMUMAB RETENTION RATE IN PATIENTS WITH PSORIATIC ARTHRITIS. IS CONCOMITANT DMARD IMPORTANT?}

B. Serrano-Benavente ${ }^{1,2}$, C.M. González-Fernández ${ }^{1,2}$, L. Valor ${ }^{1}$, I. Janta ${ }^{1}$, R. D. González-Benítez ${ }^{1}$, C. Sáenz Tenorio ${ }^{1}$, J.C. Nieto-González ${ }^{1}$, J.G. OvallesBonilla ${ }^{1}$, J. Martínez-Barrio ${ }^{1}$, M. Correyero Plaza ${ }^{1}$, L. García-Montoya ${ }^{1}$, F.J. LópezLongo ${ }^{1,2}$, I. Monteagudo Saez ${ }^{1}{ }^{1}$ Rheumatology, Hospital General Universitario Gregorio Marañón; ${ }^{2}$ Faculty of Medicine, Universidad Complutense de Madrid, Madrid, Spain

Background: The efficacy of Golimumab treatment in psoriatic arthritis (PsA) patients has been widely documented.

Objectives: The aim of this study was to analyse the long-term retention rate of golimumab and to identify independent predictors of drug retention in patients with PsA including concomitant synthetic disease-modifying antirheumatic drugs (sDMARD)

Methods: Prospective monocentric cohort of PsA patients treated with golimumab according to clinical practice. Study was approved by local Ethics Committee. Demographic and clinical variables were analysed with Cox proportional hazard regression model.

Results: 48 patients were included, 20/48 (41.7\%) oligoarticular, 19/48 (39.6\%) polyarticular and $9 / 48(18.7 \%)$ with peripheral and axial PsA. The baseline characteristics of the patients are shown in table 1.

Abstract AB0910 - Table 1. Baseline demographic and clinical characteristics of the patients.

\begin{tabular}{lc}
\hline Age -mean (SD)-years & $48.3(11.1)$ \\
\hline Female gender (\%) & $25(52.1 \%)$ \\
Mean evolution time- (SD)- years & $8.4(7.9)$ \\
TJC - mean (SD) & $4.1(4.1)$ \\
SJC - mean (SD) & $2.9(2.7)$ \\
CRP mg/dl - mean (SD) & $0.6(0.7)$ \\
DAS 28- CRP - mean (SD) & $3.7(1.5)$ \\
Concomitant DMARD (\%) & $24(50 \%)$ \\
Biological Therapy naïve (\%) & $25(52.1 \%)$ \\
\hline
\end{tabular}

Follow-up time was 89.25 patients-year. Mean survival time was 40.3 months (95\% Cl: 32.0-48.5). Age, mean evolution time and previous biological use were significant in the univariate analysis. Concomitant SDMARD had no influence on golimumab retention rate (HR: $1.3 ; 95 \% \mathrm{Cl}$ : 0.5-3.2; p: 0.6). Figure 1. When golimumab was used as first or second biologic treatment, it had a better retention rate than when it was used as third or fourth, but did not reach statistical significance (HR: 2.3 ; IC 95\%: 0.8-6.2; $p=0.1)$. 18/48 patients $(37.5 \%)$ withdrew golimumab treatment. $13 / 18(72.2 \%)$ due to lack of efficacy, $1 / 18(0.6 \%)$ due to adverse events and $4 / 18(22.2 \%)$ due to other reasons.

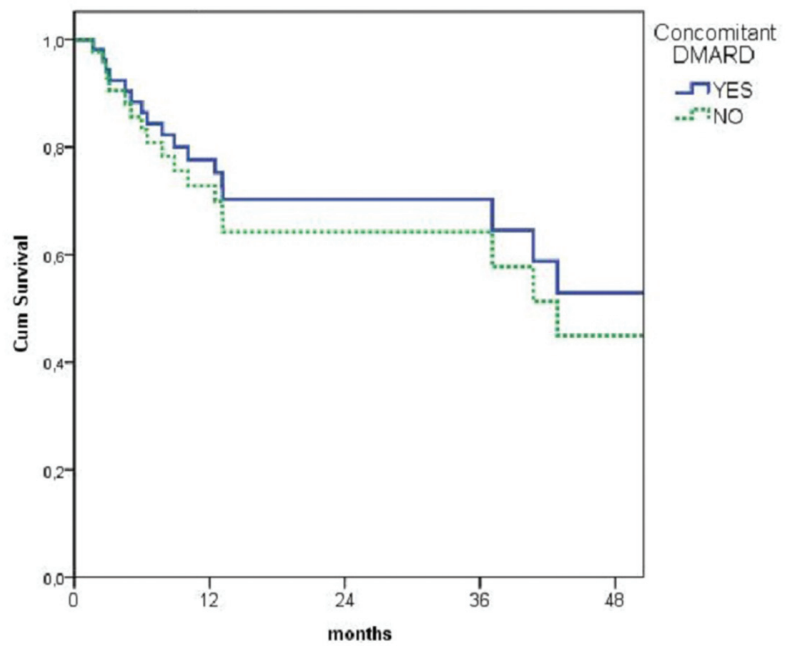

Abstract AB0910 - Figure 1. Golimumab retention rate and concomitant DMARD

Conclusions: Real-world Golimumab retention rate in patients with PsA was good and did not depend on concomitant treatment with sDMARD. When used as first or second biologic, Golimumab retention rate tended to be better.

Disclosure of Interest: None declared

DOI: 10.1136/annrheumdis-2018-eular.4111

\section{$\mathrm{AB} 0911$ \\ THE RELATIONSHIP BETWEEN NEUROPATHIC PAIN AND DISEASE ACTIVITY, SLEEP, FATIGUE, QUALITY OF LIFE IN PATIENTS WITH PSORIATIC ARTHRITIS}

C. Unal ${ }^{1}$, F. Ulutatar ${ }^{1}$, M.T. Duruoz ${ }^{2} .{ }^{1} P M R$ Department, ${ }^{2} P M R$ Department, Rheumatology Division, Marmara University School of Medicine, Istanbul, Turkey

Background: Neuropathic pain (NP) is composed of several abnormal sensations, including burning, prickling hyperalgesia and allodynia. NP is a common problem in rheumatic diseases such as rheumatoid arthritis and ankylosing spondylitis due to inflammatory processes. Previous studies showed that NP in other rheumatic diseases had a negative influence on sleep and quality of life. ${ }^{1,2}$

Objectives: To examine the relation of neuropathic pain symptoms in Psoriatic Arthritis (PsA) with demographic, clinical and functional parameters.

Methods: PsA patients according to CASPAR criteria were recruited into the study. Demographic and clinical parameters were noted. PainDETECT measurement tool was used for evaluation of NP. Physical examination such as manual muscle testing and sensory examination for hyperalgesia and allodynia was performed (pinprick and light touch test). Disease Activity Score-28 (DAS-28) was noted for disease activity. Associations of NP with quality of life, sleep and fatigue were analysed by filling out Psoriatic Quality of Life (PsAQoL), Pittsburgh Sleep Quality Index (PSQI), Multidimensional Assessment of Fatigue (MAF). PainDETECT scores were categorised as no NP ( $<12$ points), ambiguous NP (13-18 points), probable NP ( $\geq 19$ points). Group analysis was performed with Independent-Samples Kruskal-Wallis test. Spearman correlation coefficient (rho) was used for correlations between functional parameters. $p<0.05$ was accepted as significant.

Results: Forty eight PsA patients (31 female, 17 male) with a mean age 50.4 years (SD:10.0) and mean disease duration 92.2 months (SD: 90.2) were recruited into the study. The number of patients with ambiguous NP was 6 patients (4 female, 2 male) and probable NP was 12 patients ( 10 female, 2 male). The mean scores of PSQI, PSAQoL and MAF were significantly higher in patients with NP $(p<0.05)$. There was no difference in mean scores of DAS-28 and disease duration among groups. The correlations between PainDETECT and other func tional parameters were found moderate-strong as PSQI (rho=0.43, $p=0.002$ ), MAF (rho=0.44, $p=0.002$ ), PsAQoL ( $r h o=0.66, p=0.0005$ ). Also, the probability of $\mathrm{NP}$ existence increased with the age ( $\mathrm{rho}=0.40, \mathrm{p}=0.01$ ). There was no significant correlation between and clinical parameters such as disease duration and DAS 28 ( $p>0.05)$.

Conclusions: These findings suggest that a substantial number of PsA patients suffering from NP. The neuropathic pain symptoms are found to be associated with worse self-reported quality of life and sleep disturbances. It is important to consider the existence of NP in the assessment and treatment process of PSA.

\section{REFERENCES}

[1] O'Connor AB, et al. Neuropathic pain: quality-of-life impact, costs and cost effectiveness of therapy. Pharmacoeconomics. 2009; 27:95-112.

[2] Argoff CE, et al. The coexistence of neuropathic pain, sleep, and psychiatric disorders: a novel treatment approach. Clin J Pain. 2007; 23:15-22.

Disclosure of Interest: None declared

DOI: 10.1136/annrheumdis-2018-eular.6766

\section{AB0912 TWO-YEAR EFFICACY AND SAFETY OF GUSELKUMAB FOR TREATMENT OF MODERATE-TO-SEVERE} PSORIASIS: PHASE 3 VOYAGE 1 TRIAL

C.E. Griffiths ${ }^{1}$, K.A. Papp ${ }^{2}$, A.B. Kimball ${ }^{3}$, B. Randazzo ${ }^{4}$, Y. Wasfi ${ }^{4}$, S. Li $i^{4}$, Y.K. Shen ${ }^{4}$, A. Blauvelt ${ }^{5} .{ }^{1} U$ of Manchester, Manchester, UK; ${ }^{2}$ K. Papp Clinical Research and Probity Research Inc, Waterloo, Canada: ${ }^{3}$ Harvard Medical Faculty Physicians at Beth Israel Deaconess Medical Center, Inc, Boston; ${ }^{4}$ Janssen Research and Development, LLC, Spring House; ${ }^{5}$ Oregon Medical Research Center, Portland, USA

Background: Guselkumab (GUS) is an interleukin-23 inhibitor recently approved in the US for treatment of moderate-to-severe psoriasis.

Objectives: Efficacy and safety data for up to 100 wks of GUS treatment are reported.

Methods: In the VOYAGE 1 Phase 3, randomised, double-blind, placebo/active comparator-controlled trial, 837 patients were randomised at baseline to placebo (PBO) at wks0/4/12 then GUS $100 \mathrm{mg}$ at wks16/20 and $\mathrm{q} 8 \mathrm{w}$ ( $\mathrm{n}=174)$; GUS at wks0/4/12, and q8w ( $n=329)$; or adalimumab (ADA) $80 \mathrm{mg}$ at wk $0,40 \mathrm{mg}$ at wk1, and q2w through wk47 then GUS at wk52 and q8w $(n=334)$. Efficacy was assessed using nonresponder imputation through wk48 and treatment failure rules from wks52-100.

Results: Among patients randomised to GUS, or PBO $\rightarrow$ GUS at wk16, efficacy (PASI, Psoriasis Area and Severity Index; IGA, Investigator's Global Assessment) was maintained from wks52-100 with continuous GUS treatment. Among those 